\title{
Decolorization of azo dyes by local microorganisms
}

\begin{abstract}
Several local microorganisms were isolated and screened for their capabilities to decolorize selected azo dyes. Two isolates, RII and NHG have shown their capabilities to decolorize azo dyes i.e. Metanil Yellow (monoazo) and Reactive Black 5 (diazo), respectively, under aerobic condition at room temperature. 96.0 \% decolorization of Reactive Red 120 has been attained by the RII isolate. Crocein Orange G and Orange II, both have exactly the same molecular weights, were 23.7 and $68.5 \%$ decolorized, respectively, by the same isolate under agitated conditions. 66.6, 61.4 and $11.4 \%$ decolorization has been achieved by isolate NHG when tested with Direct Blue 71, Amaranth and Tartrazine, respectively. No correlation between degradation rate and molecular weight, number of azo bonds or presence of aromatic molecules has been observed.
\end{abstract}

Keyword: Azo dyes; Biodecolorization; Metanil yellow; Reactive black 5 